\title{
Study on the application of the circulating well technology in the remediation of benzene pollution in groundwater
}

\author{
Zhihui Qu', a , Hongtao Wang ${ }^{2, b}$, Zhongxin Fang ${ }^{3, c}$, Sili Yuan ${ }^{4, d}$, Zhiwei Sang ${ }^{5, e}$, \\ Wenmin Cai ${ }^{6, f}$, Yao Huang ${ }^{7, g}$, Yuhu Chang ${ }^{8, h}$, Chao Wang ${ }^{9, i}$, Yuhu Zhang ${ }^{10, j}$ \\ ${ }^{1}$ Zhongke Dingshi Environmental Engineering Co.,LTD, Beijing, China \\ ${ }^{2}$ School of Environment Tsinghua University, Beijing, China \\ ${ }^{3}$ Zhongke Dingshi Environmental Engineering Co.,LTD, Beijing, China \\ ${ }^{4}$ Zhongke Dingshi Environmental Engineering Co.,LTD, Beijing, China \\ ${ }^{5}$ Zhongke Dingshi Environmental Engineering Co.,LTD, Beijing, China \\ ${ }^{6}$ Zhongke Dingshi Environmental Engineering Co.,LTD, Beijing, China \\ ${ }^{7}$ Zhongke Dingshi Environmental Engineering Co.,LTD, Beijing, China \\ ${ }^{8}$ Zhongke Dingshi Environmental Engineering Co.,LTD, Beijing, China \\ ${ }^{9}$ Zhongke Dingshi Environmental Engineering Co.,LTD, Beijing, China \\ ${ }^{10}$ Zhongke Dingshi Environmental Engineering Co.,LTD, Beijing, China \\ aquzhihui@bjdshj.net, b714152155@qq.com, "289678826@qq.com, d595527112@qq.com, \\ e313647338@qq.com, '824341345@qq.com, '92363243730@qq.com, '1204191827@qq.com, \\ i1527586073@qq.com, ${ }^{j} 527386785 @ q q . c o m$
}

\section{Keywords: Groundwater circulation Well; Groundwater; Remediation; Benzene}

Abstract: In this paper, a city organic pollution of groundwater remediation demonstration project was the main research content. The groundwater polluted by benzene was remediated by circulation wells in the polluted area in total construction of 4 wells cycle monitoring cycle and 9 monitoring wells. The application of the technology had been continued for 28 days. The results of this study showed that: with the continuous operation of the well cycle, the concentration of benzene in groundwater decreased; after 28 days operation, removal rate of benzene was 96.5\% 98.2\%, the highest concentration detected benzene value decreased from $245.47 \mathrm{mg} / \mathrm{L}$ to $4.39 \mathrm{mg} / \mathrm{L}$; after 28 days of treatment by groundwater circulation well, the concentration of benzene was higher than that of the "People's Republic of China sewage comprehensive discharge standard" (GB 8978-1996) the limit of $0.5 \mathrm{mg} / \mathrm{L}$ three standards, the technology can deliver high concentrations of benzene decreased rapidly to low level, but the concentration is beyond the normal range of concentration, the groundwater also need further treatment.

\section{Introduction}

In recent years, with the rapid development of China's social and economic development, the development and utilization of groundwater resources has been increasing, and groundwater pollution has become increasingly prominent. Because of the unreasonable disposal of organic waste and leakage accidents has caused groundwater pollution, and many scholars began to pay attention to the study of groundwater pollution, such as the characteristics of groundwater organic pollutants scholars on the North China Plain ${ }^{[1]}$, in the Yangtze Estuary ${ }^{[2]}$, Pearl River Delta region ${ }^{[3]}$ were studied and related results are reported. Groundwater pollution is a slow process, has accumulated pollution and the lagging effect of the leak, sometimes several years or even decades later, such as landfill leachate leakage caused most of the pollution of groundwater ${ }^{[4-6]}$, and groundwater pollution remediation, relates to the pollution source analysis and pollution ways analysis, migration and transformation of pollutants in the underground mechanism research, restoration control, pollution of groundwater pollution and then carried out on the basis above. 
In recent years, the overall development of China's contaminated site remediation industry is amazing. On the one hand, the market potential is huge, the government departments at all levels attach importance to the soil and groundwater pollution investigation and remediation work, invest a lot of money to remediation, and stimulate the rapid development of the remediation project; on the other hand, the enhance on the level of application of remediation technology engineering space is increasing. Management level of engineering design and site operation of repair technology are more professional.

At present, there are many studies used for remediation of contaminated groundwater, such as groundwater circulation wells (groundwater circulation well) ${ }^{[7,8]}$, the permeable reactive barrier technology (permeable reactive barrier) ${ }^{[9,10]}$, soil vapor extraction technology (soil vapor extraction), ${ }^{[11-12]}$ (air sparging in-situ air sparging) ${ }^{[13,14]}$. However, the groundwater pollution remediation project in China to carry out the actual groundwater pollution remediation experience is still less, compared to developed countries for decades, comprehensive accumulation of our groundwater pollution remediation industry is very inadequate. Although the extraction processing technology repair technology from the development of the industry at the beginning of the development of relying solely on the management of projects, development to the application of in situ air disturbance (Air sparging), practice, try to repair the in situ chemical oxidation and monitoring natural attenuation of different types of technology, but because of the particularity of different types and concentrations of pollutants in contaminated sites, especially the underground environment of different hydrogeological conditions, groundwater pollution control project has more complexity and uncertainty, groundwater pollution remediation project successfully completed a handful of domestic.

As the groundwater circulating well technology in the in-situ remediation of contaminated groundwater, the European and American countries have a wide range of engineering applications for organic contaminated groundwater site ${ }^{[15]}$. The technology is to use the aeration to form underground water wells, so that the pollution material with the air to the ground above the collection and processing technology.

In this paper, the main research contents of this paper are as the main research content of the remediation of organic contaminated groundwater sites in a city. The pressure inside the well aeration cycle is $2.02 \times 10^{5} \mathrm{~Pa}$, the application of the technology after 28 days of treatment, the concentration of pollutants in underground water benzene decreased sharply, experimental study of this site, provides reference and experience in the implementation of the case for the practical application of this technology.

\section{Circulation well design}

In order to ensure the effective implementation of groundwater, based on the working principle of wells stripping analysis, the design of the internal structure of circulation well was made and determine wellbore length, borehole diameter and flower hole position and a series of parameters. The application of the circulation well and monitoring well is shown as follows. 


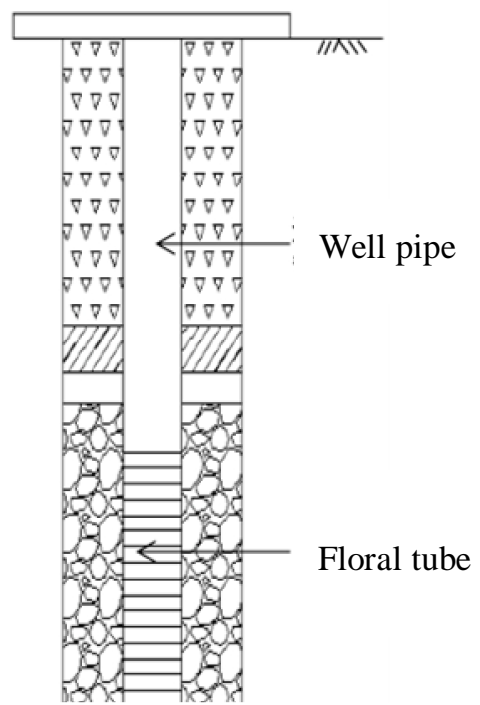

Fig. 1 Schematic diagram of groundwater circulation well

\section{Site circulation well and monitoring well arrangement}

Groundwater pollution field medium of this study is evenly distributed in the sand, the 4 cycle wells in the pollution area was layout and in the repair process, repair effect monitoring around laid 9 monitoring wells, the specific layout is as below.

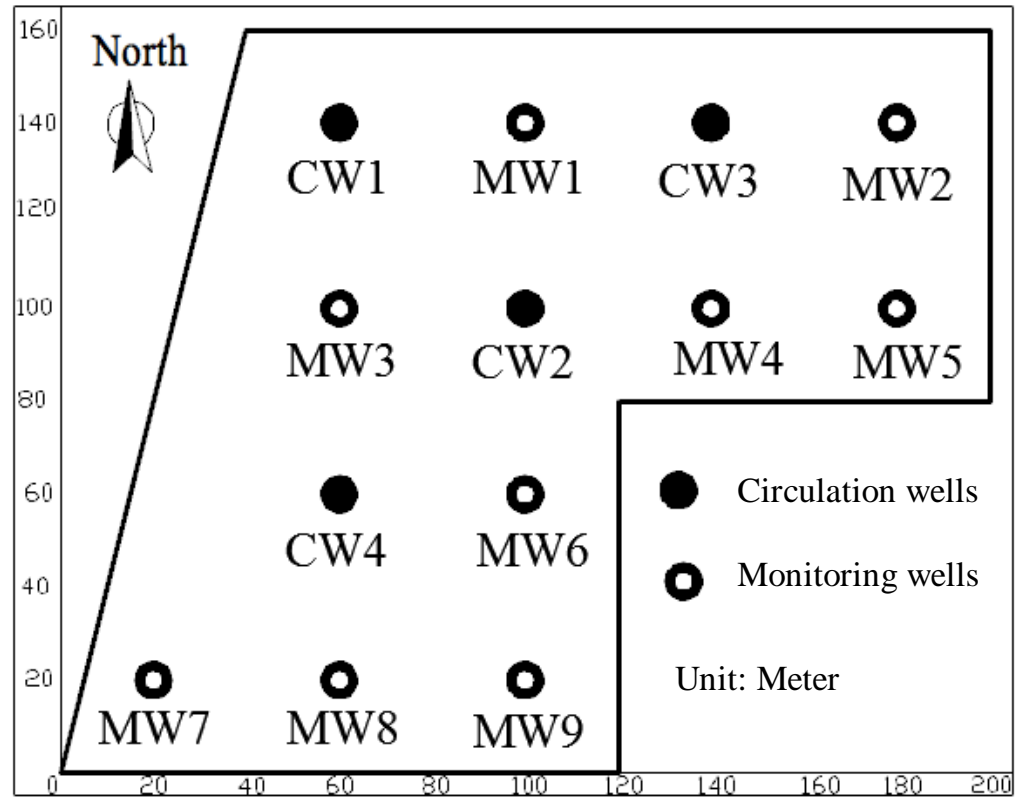

Fig.2 Distribution of circulation wells and monitoring wells

\section{Results and analysis}

Groundwater pollution benzene distribution change

Before the application of groundwater circulation wells, the pollution of benzene distribution in the contaminated area as shown below. 


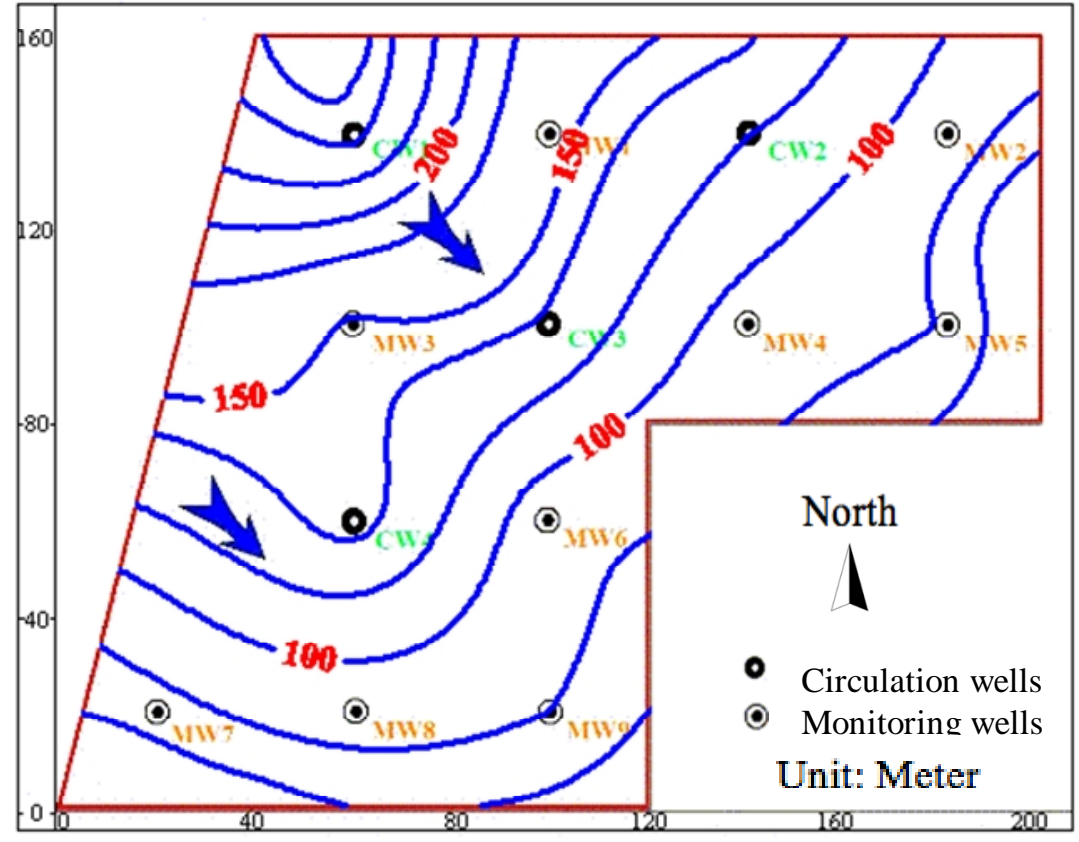

Fig. 3 Distribution of benzene

The concentration of benzene concentration in the circulating well CW1 is $245.47 \mathrm{mg} / \mathrm{L}$, which is located in the northwest corner of the area, before the circulation in the well is not running. Monitoring the concentration of benzene concentration in the well MW7 is $74.31 \mathrm{mg} / \mathrm{L}$, which is the minimum concentration detected in the 13 wells. The direction of groundwater flow in the study area is from northwest to Southeast, and the concentration of pollutants in the northwest of the high concentration center gradually decreases from the northwest to the southeast.

Benzene removal during the well cycle operation

Though the running of the cycle wells, on the day $0,7,14,21,28$ days, respectively, removal of pollutants in the groundwater was discussed, and benzene removal rate changes with time was shown below. 

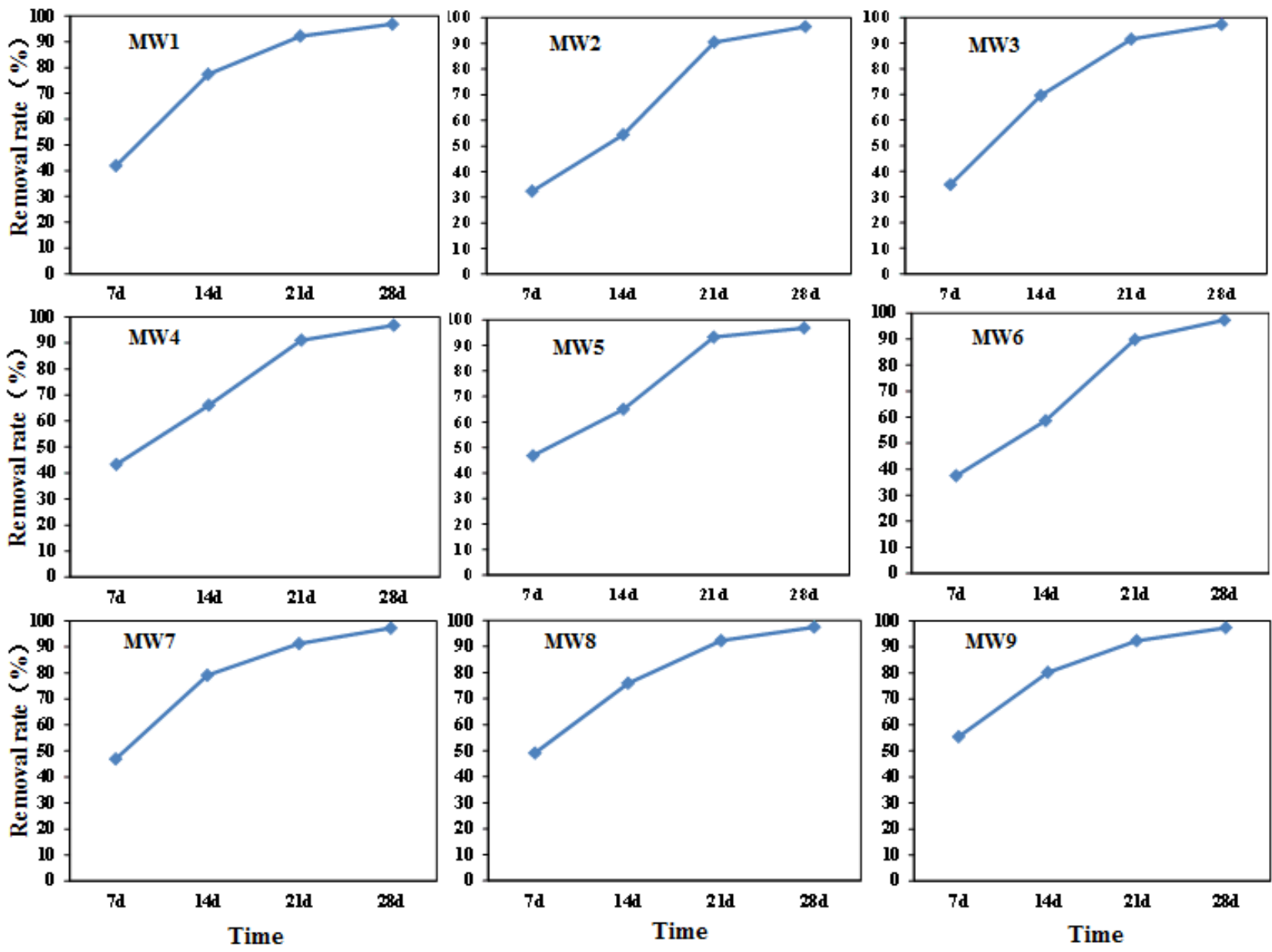

Fig.4 The change of concentration of benzene over time

From the above showed, with the continuous operation of the circulation well, the removal rate of benzene in groundwater of the 9 monitoring wells has been gradually increased. The highest removal rate of benzene was $55.4 \%$ and the lowest removal rate was $32.3 \%$ during 7 days. In the well cycle operation of 14 days, the removal rate of benzene groundwater is $54.4 \% \sim 80.2 \%$, wells cycle 28 days, the removal rate of benzene groundwater was $89.9 \%$ 93.3\%, in the well cycle 28 days, groundwater benzene removal rate was $96.5 \%$ 97.5\%.

\section{Repair effect of circulating well on benzene pollution of groundwater}

28 days after treatment of groundwater circulation technology, the remediation effect of groundwater pollutants benzene was shown in the following table. 
Table 1 The remediation effect of groundwater circulation well on benzene

\begin{tabular}{cccc}
\hline \multirow{2}{*}{ No. } & \multicolumn{2}{c}{ concentration $(\mathrm{mg} / \mathrm{L})$} & Removal rate $(\%)$ \\
\cline { 2 - 3 } CW1 & 245.47 & $28 \mathrm{~d}$ & 98.2 \\
CW2 & 137.81 & 3.39 & 97.7 \\
CW3 & 120.73 & 2.33 & 98.1 \\
CW4 & 148.98 & 3.94 & 97.4 \\
MW1 & 155.39 & 4.89 & 96.9 \\
MW2 & 90.82 & 3.20 & 96.5 \\
MW3 & 145.37 & 3.94 & 97.3 \\
MW4 & 90.81 & 2.93 & 96.8 \\
MW5 & 79.82 & 2.54 & 96.8 \\
MW6 & 86.71 & 2.32 & 97.3 \\
MW7 & 74.31 & 2.08 & 97.2 \\
MW8 & 88.11 & 2.20 & 97.5 \\
MW9 & 80.37 & 2.16 & 97.3 \\
\hline
\end{tabular}

After operation of groundwater circulation wells for 28 days, the highest concentration of benzene in the circulation well decreased from $245.47 \mathrm{mg} / \mathrm{L}$ to $4.39 \mathrm{mg} / \mathrm{L}$, the removal rate was $98.2 \%$, the lowest in the circulation well concentration decreased from $120.73 \mathrm{mg} / \mathrm{L}$ to $2.33 \mathrm{mg} / \mathrm{L}$, the removal rate was 98.1\%; the highest concentration monitoring wells of benzene value decreased from $155.39 \mathrm{mg} / \mathrm{L}$ to $4.89 \mathrm{mg} / \mathrm{L}$, removal rate as of $96.9 \%$, the lowest value of benzene concentration monitoring wells decreased from $74.31 \mathrm{mg} / \mathrm{L}$ to $2.08 \mathrm{mg} / \mathrm{L}$, the removal rate was $97.2 \% .13$ days after treatment, 4 wells and 9 wells of groundwater contamination benzene concentration range of $4.39 \mathrm{mg} / \mathrm{L} \sim 2.08 \mathrm{mg} / \mathrm{L}$, the removal rate of benzene is $96.5 \%$ 98.2\%. The value of benzene concentration is higher than that of the People's Republic of China municipal wastewater comprehensive discharge standard (8978-1996 GB) benzene level three standard limit value $0.5 \mathrm{mg} / \mathrm{L}$.

\section{Conclusions}

(1) Groundwater circulation well technology in the treatment of benzene pollution using groundwater pollutants, benzene concentration decreased with the continuous operation of wells cycle, running for 28 days, the highest concentration detected benzene value decreased from $245.47 \mathrm{mg} / \mathrm{L}$ to $4.39 \mathrm{mg} / \mathrm{L}$, the removal rate reached $8.2 \%$.

(2) The pollutant removal efficiency of benzene with prolonging the treatment time and the underground circulation well gradually increased, after 7 days of treatment, the groundwater in the benzene removal rate was 32.3\% 55.4\%; after 14 days of treatment, the removal rate of benzene groundwater was $54.4 \% \sim 80.2 \%$, after 28 days of treatment, the removal rate of benzene groundwater was $89.9 \%$ 93.3\%, after 28 days of treatment, water benzene the removal rate of $96.5 \%$ 97.5\%.

(3) The research and application of groundwater circulation wells after 28 days of treatment, whether in the center of the monitoring points near the pollution or pollution monitoring point away from the center, the pollutant removal rate of benzene water was almost the same, the circulation well design was scientific and reasonable, and can uniform removal of pollutants in the groundwater of benzene.

(4) Groundwater circulation well technology after 28 days of treatment, the removal rate of benzene groundwater was $96.5 \% \sim 97.5 \%$, but the concentration of benzene was higher than that of the "People's Republic of China integrated wastewater discharge standard" (GB 8978-1996) limit 0.5mg/L 
benzene standard level three. It indicated that the technology can deliver high concentrations of benzene pollution fastly reduced to low level however, the value of concentration was still beyond the normal range, the groundwater also need further treatment.

\section{References}

[1] SHI Jiansheng, WANG Zhao and ZHANG Zhaoji. Ecology and Environmental Sciences. Vol.20,No.11 (2011),p.1695-1699.

[2] LIU Zheng-tao, JIANG Fu-xin and WANG Wan-hua . Research of Environmental Sciences. Vol.19,No.2 (2006),p.1-5.

[3] GUO Xiuhong, CHEN Xi and HUANG Guanxing. Environmental Chemistry.Vol.25,No.6 (2006) ,p.798-799.

[4] ZHAO yongsheng. Journal of Jilin University (Earth Science Edition).Vol.37,No.2 (2007) ,p.303-310.

[5] ZHAO yongsheng. Environmental Sciences.Vol.23(2012), p.83-88.

[6] Appelo C.A.J: Geochemistry Groundwater and Pollution (A Balkema, Rotterdam:The Netherlands ,1994).

[7] FRAN , GILMORE T and PINTO M.J: Water Resour Res.Vol.32,No.8 (2006) ,p. 2383-2399.

[8] GVIRZMAN H and GORELICK S.M: Transport in Porous Media , Vol.8, No. 1(1992),p.71-92

[9] CHIU Chuenhuey, LIN Tsairfuh and HUNG Weinung: Sustain Environ Res. Vol.23,No. 1 (2013),p.53-60.

[10] LIU Yuanyuan, GAO Song and QIU Mingying. Ecology and Environmental Sciences.Vol.21,No.4 (2012) ,p.733-736.

[11] SOARES A.A, PINHO M.T and ALBERGARIA J.T: Water Air and Soil Pollution, Vol.223, No.5(2012),p.2601-2609 .

[12] Wang Peng, Wang Feng and Chen Suyun. Environmental Engineering.Vol.29 (2011),p.171-174.

[13] GHABAYEN S, ABUALTAYEF M, RABAH F, et al . Effectivenessof air sparging technology in remediation of gaza coastal aquifer from gasoline products . Journal of Environmental Protection, Vol.4,(2013),p.446-453 .

[14] HU Liming, WU Xiaofeng, LIU Yan, et al . Physical modeling of air flow during air sparging remediation . Environ Sci Technol, Vol.44,No.10 (2010), p.3883-3888 .

[15] United states Environmental Protection Agency. Field Applications of In Situ Remediation Technologies:Ground-Water Circulation Wells. Solid Waste and Emergency Response, 1998.8 